\title{
Aging baby boomers to challenge Golden State
}

Seniors who exercise regularly are less susceptible to many common illnesses. alifornia is about to be hit by an "age wave" of people 60 years and over. Elders are projected to account for an unprecedented one-fifth of the state's population in just a decade, according to the 2009-2013 California State Plan on Aging, straining the already thinly-stretched services for senior citizens. UC research and outreach are helping Californians fulfill the promise of their golden years (see page 195).

\section{"Silver tsunami"}

Driven by aging baby boomers and longer life spans, this "silver tsunami" is expected to swell the state's elderly population by $40 \%$ to nearly 9 million by 2020 and to double it from the current 6.4 million to 11.5 million by 2030. Elders' greatest needs will include transportation so they can maintain independence and avoid isolation, caregivers so they can stay in their homes (see page 201), and health care for the mental and physical ailments that can come with age. These needs can be exacerbated in rural areas. "As the elderly have to stop driving due to vision and health problems, how will they get to doctor appointments and senior centers?" asks Beth A. Ober, UC Davis professor of human development.

Within the elderly population, those 85 years and over are more likely to have severe disabilities and chronic conditions such as heart disease, diabetes and dementia. These so-called "old-old" will more than triple in California from the current roughly 600,000 to nearly 3 million by 2050, and more than three-fifths will be women due to their longer life expectancies. Other particularly at-risk elders include the 20\% with limited English skills

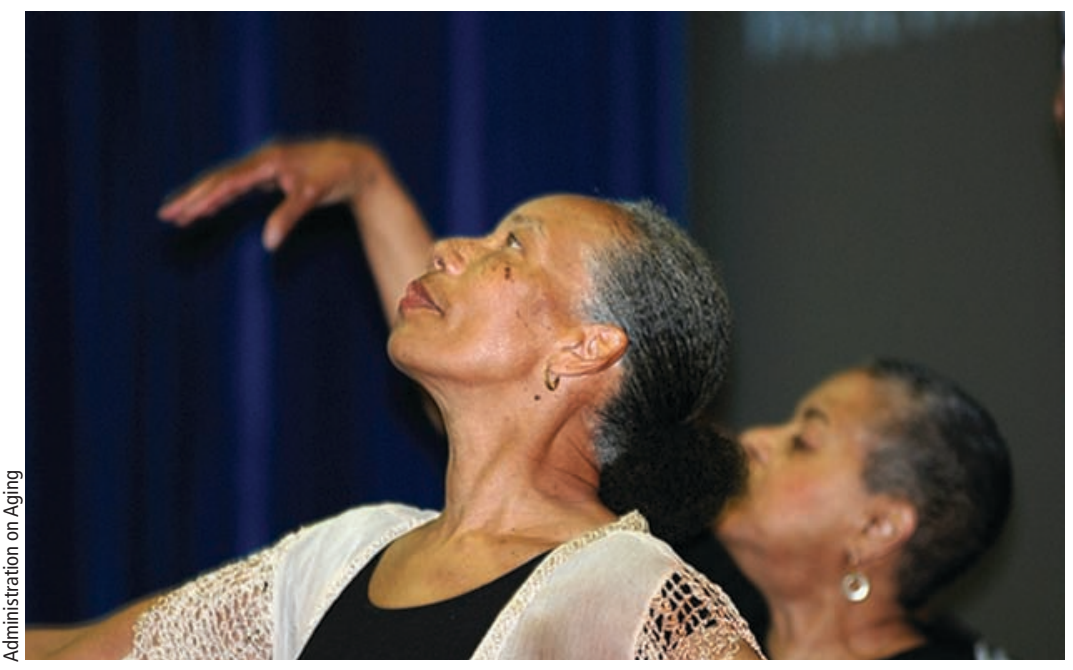

(see page 189), the $30 \%$ living in or near poverty and the $50 \%$ with disabilities. In addition, Latino and black seniors may be at higher risk for Alzheimer's disease (see box).

\section{Optimal aging}

But getting older does not have to mean deteriorating mental and physical health. "The aging process is plastic," says Carolyn Aldwin, former UC Davis professor of human development, who is now

\section{Minority outreach and Alzheimer's disease}

The risk of Alzheimer's disease increases with advanced age and cardiovascular disease, and while the first is color blind, the second is not. Blacks are more likely to have high blood pressure (hypertension) and Latinos are more likely to have diabetes, which increases the risk of hypertension. But does this translate into a greater likelihood of Alzheimer's disease?

Study results are mixed and researchers at the UC Davis Alzheimer's Disease Center are investigating what relationship exists, if any. The most common form of dementia (or cognitive decline), Alzheimer's disease causes memory loss, disorientation and personality changes.

"We study healthy aging and cognitive impairment in minorities," says Charles DeCarli, Alzheimer's Disease Center director. "Our goal is understanding their special needs."

The Center conducts minority outreach throughout the Central Valley as well as in the Oakland area, taking the unique approach of sending representatives into communities rather than the typical approach of expecting residents to come to a clinic.

"If you go out into the community and talk to people, that breaks down barriers and they are more willing to come to the clinic," DeCarli says. Latinos are among the fastest-growing segments of California's elderly population, increasing the urgency of providing effective outreach to minorities.

Besides helping recruit a more representative sample for the Center's study, this community outreach teaches minority elders and caregivers about dementia. "It's good for the individuals attending and will ultimately benefit the whole population," DeCarli says.

- R. Meadows 


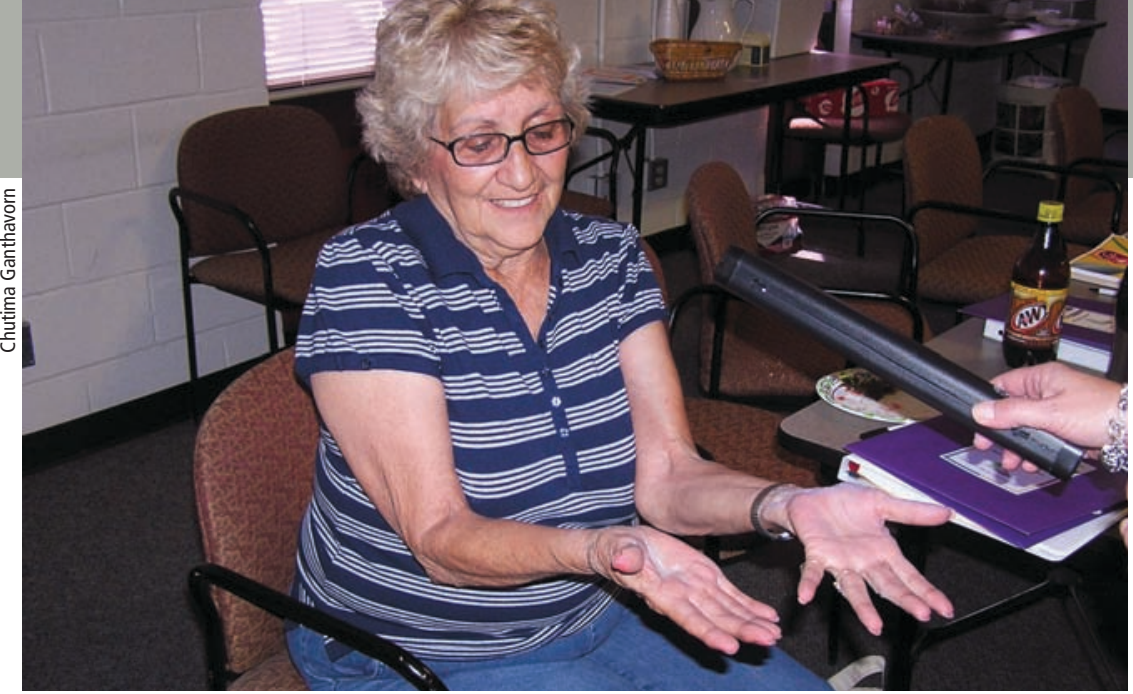

During UCCE's

"Make Food Safe for Seniors" workshop for grandparents at the California Family Life Center in Hemet, a Glo-Germ Hand Washing Kit was used to demonstrate how well a participant cleaned her hands.

at Oregon State University, Corvallis. "Dementia, osteoporosis, cardiovascular disease and the like are not inevitable."

How we age is primarily affected by how we live. "Surprisingly, just a few factors affect aging in many different organ systems," says Aldwin, an editor of the 2007 book Handbook of Health Psychology and Aging (Guilford Press). The keys are not smoking, good nutrition and regular exercise:

- Smoking tobacco increases the risk of a host of illnesses from lung cancer and heart disease to osteoporosis and dementia. This is partly because smoking damages collagen, the primary protein found in connective tissue throughout our bodies. Besides being a health threat, collagen damage causes wrinkles that make people look more aged.

- Poor nutrition can lead to glucose intolerance and ultimately diabetes, which can cause high blood pressure, cardiovascular disease and nerve damage. In contrast, diets rich in whole grains, fruits and vegetables provide nutrients vital to organ function as well as antioxidants that protect against aging at the cellular level (see page 167).

- Exercise benefits lung and cardiovascular health, and may protect against colon cancer. In addition, seniors who exercise regularly are less susceptible to catching

\section{For more information}

\section{California Department of Aging} http://www.aging.ca.gov

California State Plan on Aging 2009-2013 http://www.aging.ca.gov/legislation/California_State_ Plan_on_Aging_AoA_2009-2013_06-30-2009.pdf

Optimal Aging

http://groups.ucanr.org/elderly/documents/Aging Issues5831.pdf colds, and weight-bearing exercise helps counteract osteoporosis.

Another key to optimal aging is how we handle stress (see page 183). “Elders can be more vulnerable to stress physiologically," Aldwin says. "But people can also develop appraisal and coping strategies that allow them to become more resilient with age." Good nutrition, regular exercise and reducing stress are also good for our brains as we age, says UC Davis' Ober. Other ways to protect brain function and memory include having an active social life and keeping your mind active, for example by learning a new language (see page 174).

\section{Elder care}

Outreach is key to helping elders age optimally, including teaching their caregivers what they need. Most elder caregivers are family members, but about one-fifth are registered with and paid for by In-Home Supportive Services (IHSS), statefunded county programs for low-income seniors. IHSS caregivers help with the essentials of daily living from housekeeping to meal preparation to personal care. "Unfortunately, there is no standardized training for registered caregivers," says Gloria Barrett, former director of UC Cooperative Extension (UCCE), Sacramento County

To help close this gap, IHSS and UCCE developed a training program based on a survey of about 1,000 registered caregivers in Sacramento. "Many are of limited income and education, and they represent diverse cultural and ethnic groups," Barrett says. A casualty of county budget cuts, the training was offered in English, Spanish, Hmong and Russian, and covered a wide range of needs, from promoting mental and physical health to identifying the signs of dementia to preventing falls, the leading cause of injury and death in elders. The curriculum includes basics such as how to prepare nutritious meals and remove spoiled food from refrigerators. "This program was fairly unique," Barrett says. "In other areas of the state, there may not have been any training at all."

And soon, there may also be a dearth of registered caregivers. "The state plans to cut or eliminate IHSS services," Barrett says. To close the $\$ 18$ billion dollar budget gap projected for 20102011, the Governor's office has proposed cutting the IHSS budget by $\$ 750$ million, according to the state Legislative Analyst's Office. This is about half of the program's current budget and would jeopardize services to hundreds of thousands of the seniors currently participating statewide.

Regardless of who provides the care, California's growing elder population will intensify the need for caregiver training. "We need to provide training even if family members take over most of the caregiving," Barrett says. "It's important that this type of work continue."

- Robin Meadows 